\title{
CONTROL 4DOF TELE-OPERATION MANIPULATOR
}

\author{
Tu Diep Cong Thanh \\ University of Technology, VNU-HCM \\ (Manuscript Received on April $5^{\text {th }}$, 2012, Manuscript Revised May 30 ${ }^{\text {th }}, 2013$ )
}

ABSTRACT: Tele-operation manipulator (TM) is well-known as thebest solution for interacting between humans and the unsafe environment such as dangerous, toxic, infectious or sterile.In this study, a low cost TM system is introduced. In addition, the network control algorithms to overcome teleoperation are proposed.

KEYWORDS:Tela-operation, Control, LAN

\section{INTRODUCTION}

Tele-Operation Manipulator (TM) system is a remote control manipulator consists of two arms: the master and slave. Slave manipulator will be controlled to perform the same motion as master manipulator. To implement this control, master manipulator will be controlled by human. The desired motion of the master manipulator will be recognized by sensors and these values will be transmitted via LAN to the slave manipulator controller.

In 1898, Nikola Tesla made boat control model using radio in New York first to now, the TM has a history of development over a century [1]. TM system as the first true master - slave is made a pure mechanical structure is benevolent R. Goertz late in 1940 at the National Laboratory Argone [2]. In 1954, Goertz's team developed the first electro mechanical manipulator with feedback servo control. With the development of more modern techniques, the TM system appear in many areas more efficient service to people such as explosives detection arm of national defense and arm on the spacecraft, the main in space [3], hand-picking machine of nuclear fuel in nuclear power industry, the submersible manipulator on the seabed studies [4], and especially the type of arm surgery in remote health [5].

One of the outstanding research of robots for medical applications such as manipulator system for remote microsurgery institute KAIST, Korea [6] and surgical manipulator system accuracy in medicine at the University of Washington , USA [7]. TM control to execute as well as the ability to monitor and respond in real time, a number of studies related to model algorithms and system control are presented, such as adaptive control using a control algorithm slide is presented by Plato [8], techniques to reduce transmission time over the network in control TM was suggested by Lee [9], Sano technical proposal in the time delay compensation control TM [10], with Towhidkhah modeling and predictive control

Trang 26 
[11], and robust control with random time delay proposed by Prokopiou [12], etc..

In this study, a low cost TM system which is attended to apply to healthcare service is presented. Regarding to healthcare service, the TM system should be respected to low costwith acceptable error and strong robustness without regard to external environments and reference inputs. For the purpose, a PID controller as well as network control algorithm are applied to control TM system with four degrees of freedom (4DOF) via LAN. Results obtained will be presented through experiment.

\section{EXPERIMENTAL SETUP}

The overview of system and schematic diagram of system are presented in figure 1 and figure 2 respectively.

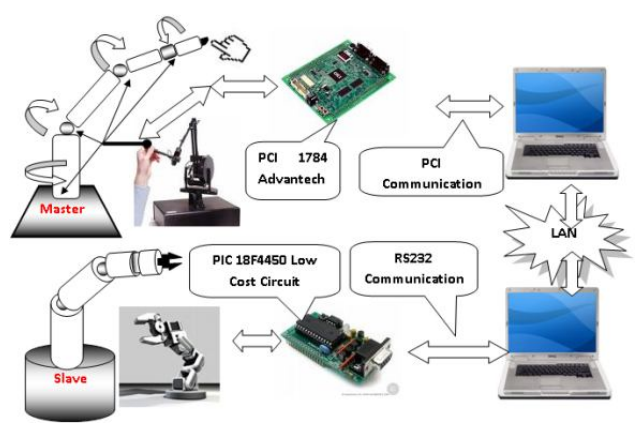

Fig 1. Overview of the proposed TM system

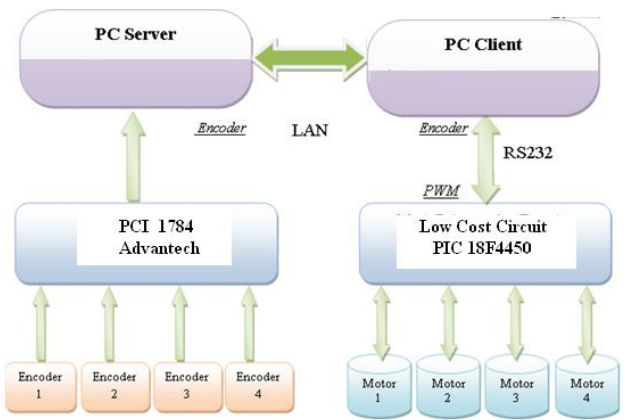

Fig 2. Schematic diagram of system
The system includes master manipulator is controlled by human and enforce slave manipulatormotion the same with the master manipulator motion. Parametersof motionof the master manipulator are recognized by the encoders (USDigital S5 Optical 1024R/P) and sent to PC server (computer 2.4 GhzPentumIV) through PCI 1874 circuit. PC server transmits these informations to the PC clientvia LAN (computer Pentum IV2.4 Ghz) as well as getting back the responese of 4 DOF TM. To control slave manipulator, PC server will compute the control signals and sent these signals to low cost circuit using microcontroller PIC 18F4450 through PC client via LAN. Control software is coded based on C\#, and the phoptograph of experinental system is shown in figure 3.

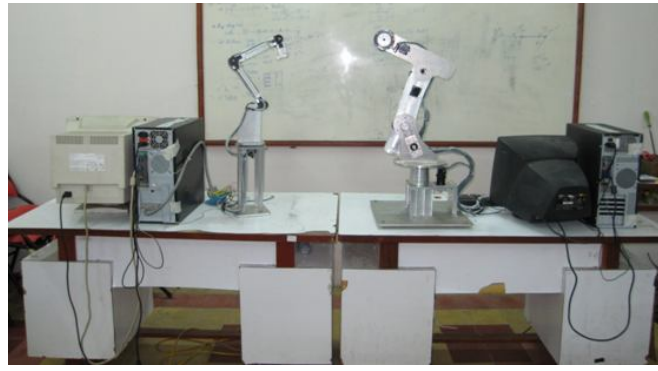

Fig 3. Photograph of the experimental apparatus

\section{CONTROL SYSTEM}

\subsection{The overall of control system}

The overall of control system is shown in figure 4. The system will include control algorithms on the PC server, PC client, the algorithm for control circuit using PIC 18F4450 and PIC 18F4431. 


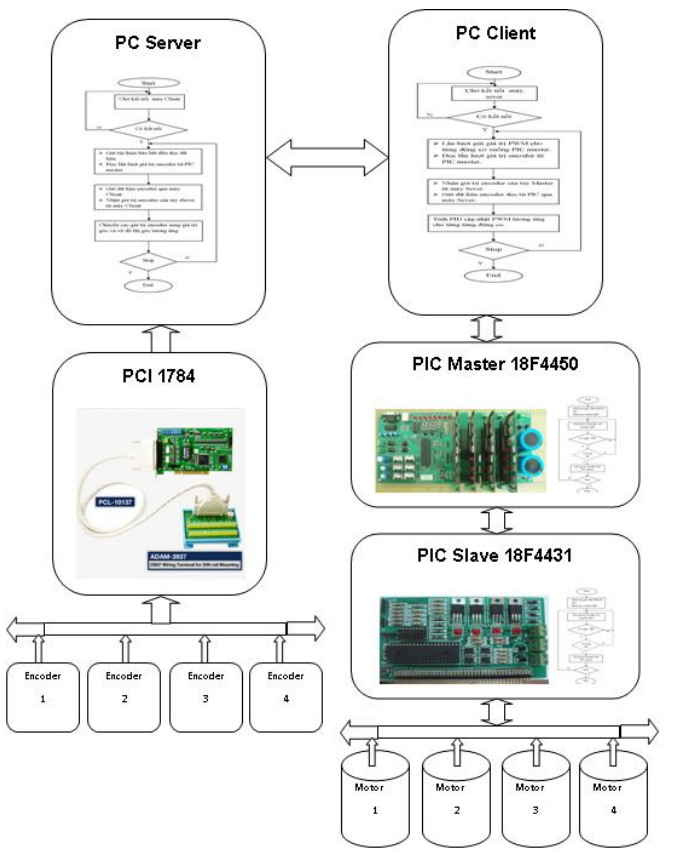

Fig 4. The overall of control system

\subsection{Control algorithm on the $\mathrm{PC}$ server}

The flowchart of PC serveris presentedinfigure

When the programstarted, the PC server will send the requested connection tothe PC Client and wait for connect. When two computers is connected, the PC server will perform the work as follows:

- Check the start point of master manipulator

-Read the encoder values of the joint angles

-Send these values to PC Client via LAN

-Waitto receive signal response of the slave manipulator

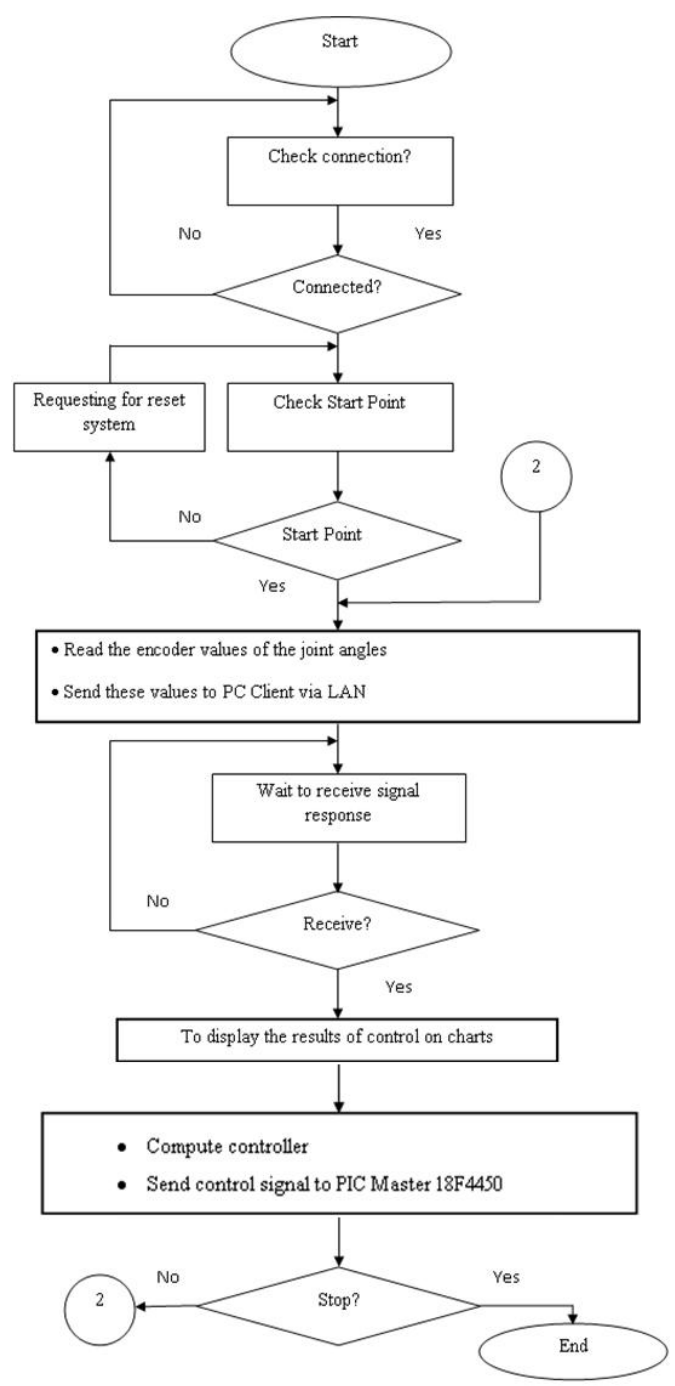

Fig 5. The flowchart of PC server

-To display there sults of control on charts

-Compute the controller

-Send control signal toPC Client

-To repeat the program until receiving the stop signal

\section{Trang 28}


TAP̈ CHÍ PHAர் TRIEÂ KH\&CN, TAR̈ 16, SOÁK2- 2013

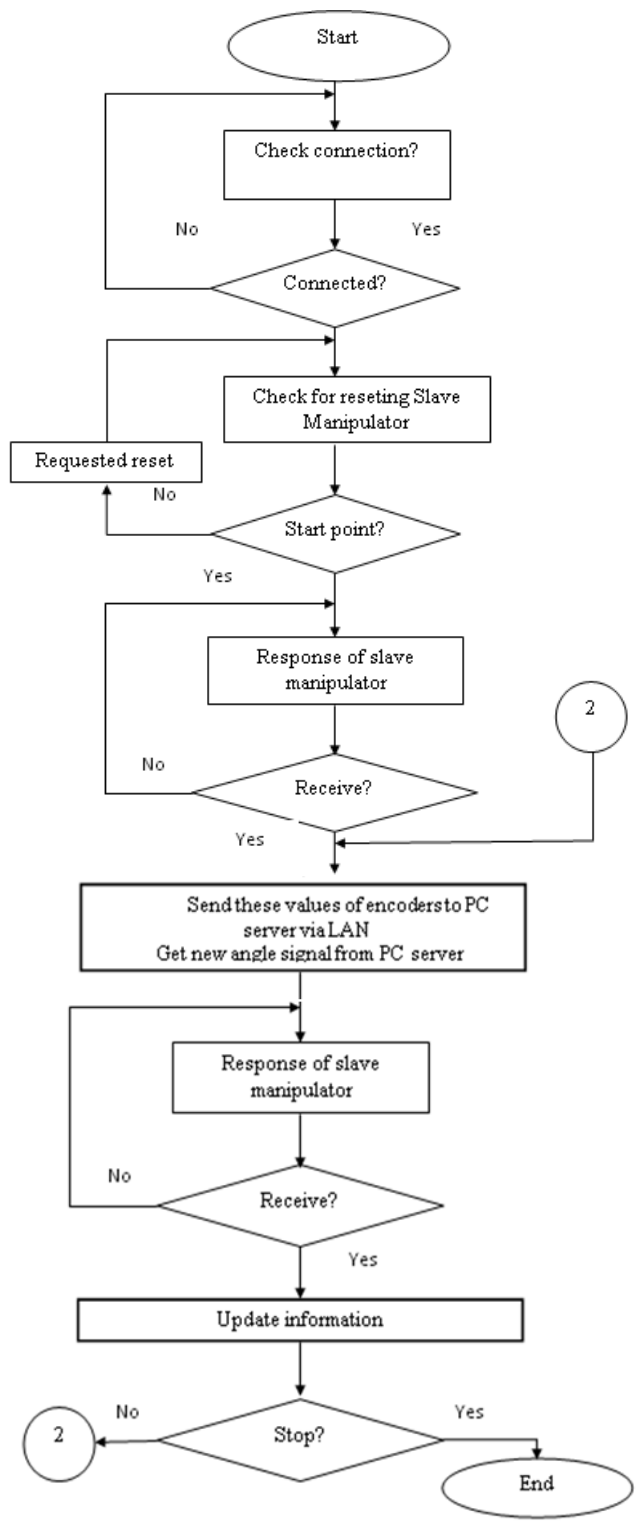

Fig 6. The flowchart of PC Client

\subsection{Control algorithm on the PC Client}

The flowchart of PC Clientis presentedinfigure 6 . Whenthe programstarted, the PC Client will send the requested connection tothe PC server andwait forconnect. When two computersis connected, the PC clientwill performthe workas follows:
- To start communication RS232 with motor control circuits - PIC Master 18F4450

- Send a requested-reset of slave manipulator

- Wait for the position feedback signal

- Send these values of encoders to PC server via LAN

- Get new angle signal from PC server

- Send control signal to PIC Master 18F4450

- Wait to receive feedback on the signal response

- To repeat the program until receiving the stop signal

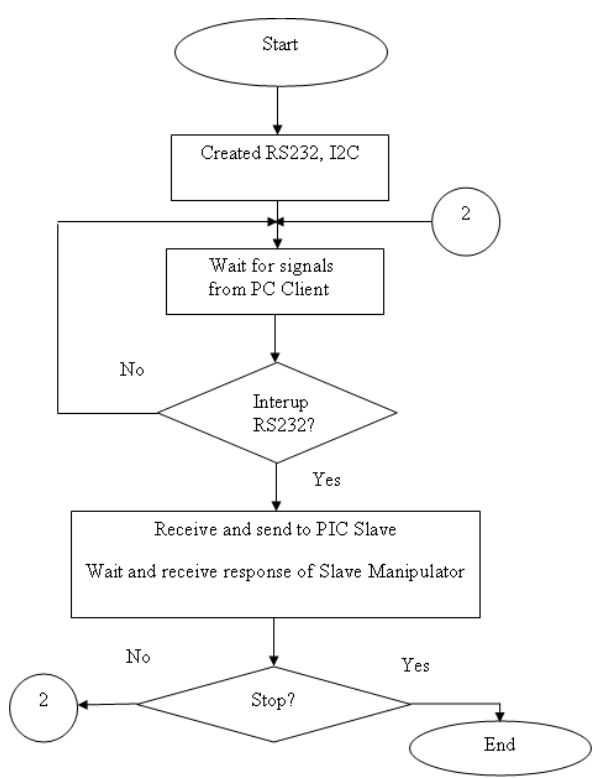

Fig 7. The flowchart on the circuit PICMaster $18 \mathrm{~F} 4450$

\subsection{Algorithm for PIC Master $18 F 4450$}

The flowchart on the circuit PIC Master 18 F4450 is shown in Figure 7. PIC Master $18 \mathrm{~F} 4450$ will perform the work as follows:

-CreatedRS232connectionto PCClient

-ConnectwithI2CPIC Slave 18F4431

-Getthevalue ofPWMpulsesfrom PC 
ClientandtransmittedtotheSlavePIC18F4431

-GetencodervaluefromthePICSlave 18F4431

and send toPC Client

-Torepeat theprogramuntilreceiving thestop

\subsection{Algorithm for PIC Slave 18F4431}

The flowchart on the circuit PICSlave $18 \mathrm{~F} 4431$ is showninFigure8. PICSlave 18F4431 will performthe workas follows:

- CreatedtheQEImodule, PWM

-GetconnectedwithI2CMasterPIC18F4450

-Getthevalue ofPWMpulsesfromthe

MasterPIC18F4450

-Send encodervaluestoPICMaster18F4450

-Torepeat theprogramuntilreceiving thestop signal

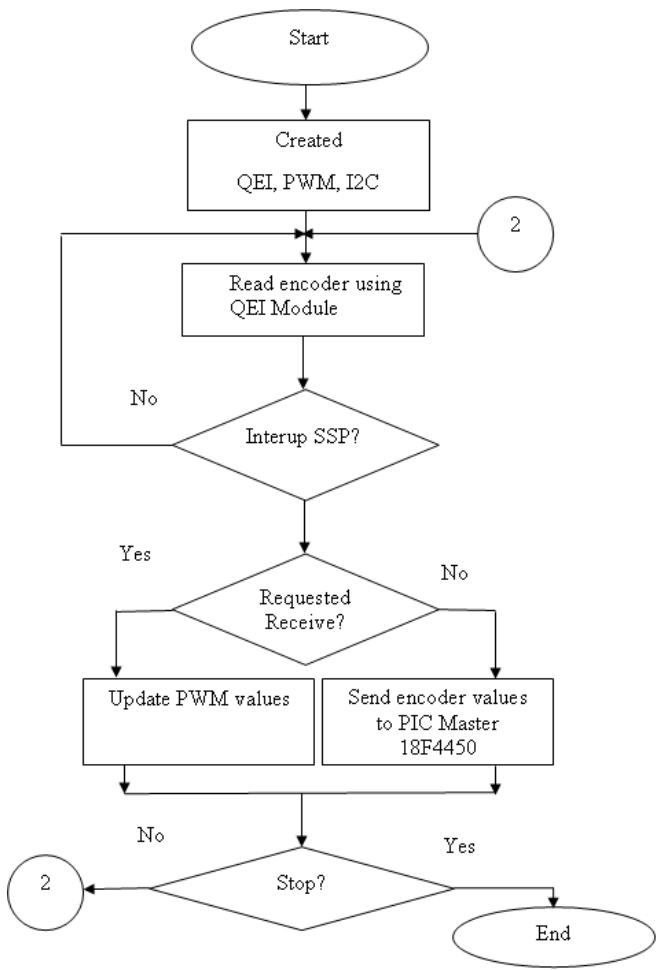

Fig 8. The flowchart on the circuit PIC Slave $18 \mathrm{~F} 4431$

\subsection{PID Controller to Control Motor}

The strategy of PID control has been one of the sophisticated methods and most frequently used in industry. This is because that the PID controller has a simple form and strong robustness in broad operating area. The structure of the PID control algorithm is shown in Fig. 9.

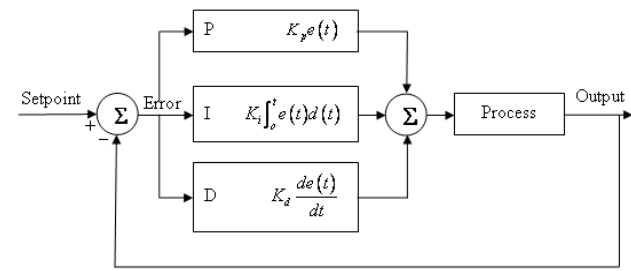

Fig 9. The structure of the PID control algorithm

The PID controller output can be expressed in the time domain as:

$u_{f}(t)=K_{p} e(t)+\frac{K_{p}}{T_{i}} \int_{0}^{t} e(t) d t+K_{p} T_{d} \frac{d e(t)}{d t}$

Taking the Laplace transform of (1) yields:

$U_{f}(s)=K_{p} E(s)+\frac{K_{p}}{T_{i} s} E(s)+K_{p} T_{d} s E(s)$

The resulting PID controller transfer function of:

$$
\frac{U_{f}(s)}{E(s)}=K_{p}\left(1+\frac{1}{T_{i} s}+T_{d} s\right)
$$

A typical real-time implementation at sampling sequence $\mathrm{k}$ can be expressed as:

$$
\begin{aligned}
& u_{f}(k)=K_{\rho} e(k)+u(k-1) . \\
& +\frac{K_{\rho} T}{T_{s}} e(k)+K_{\rho} T_{d} \frac{e(k)-e(k-1)}{T}
\end{aligned}
$$

\section{Trang 30}


$e(k)=y(k)-x(k)$

where $u_{f}(k), e(k), y(k)$ and $x(k)$ are the output of conventional PID controller, the error between the desired set point and the output, the output and the desired set point, respectively.

The effectiveness of the proposed algorithm will be demonstrated through experiment.

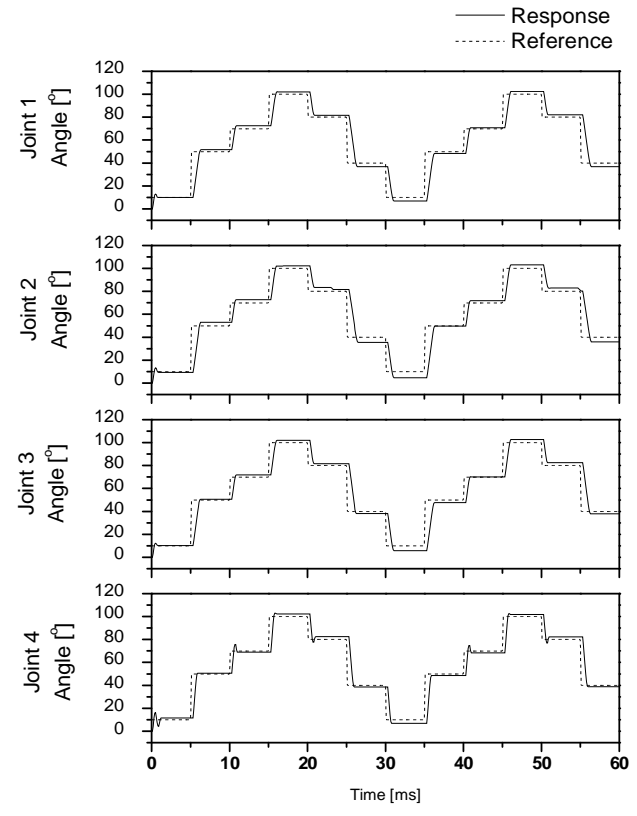

Fig 12. Step response of PID Controller

\section{EXPERIMENTAL RESULTS}

At first, PID controller is applied for control the motion of slave manipulator. The control parameters of PID controller are chosen through trial and error. And there are $K_{p}=1.5 \times 10^{-3}, \quad K_{i}=0.15 \times 10^{-3} \quad$ and $K_{d}=0.2 \times 10^{-3}$. The experimental result of stepresponse of TMare shown in figure
12.From figure 12, it shows that response of system is stable. Time delay is happened due to the system response. Actually, time delay is sampling time which is set to control TM via LAN and it is 100 milliseconds. However, this is acceptable for low cost TM system which is applied to healthcare service.

In addition, from Fig. 12, with fast changes of joint angles, and performances with good tracking are also obtainedwith respect to step inputs. The errors are low and approximate of $2 \%$ of input amplitude.

In order to improvement control performance of system, triangle form and sinusoidal form are tested, and the experimental result is shown in figure 13 and figure 14 respectively.From experimental results, it is shown that the response of system with respect to PID controller is stable and good performance. Time delay is more happened with respected to sinusoidal form. It is because of the response of control system. The system is limited with the signal inputs which have the frequency is greater than $2 \mathrm{~Hz}$.

Finally, doing practice with movement of master manipulator and checking performance of salve manipulator. Experimental result is shown in figure 15. And it is no doubt that the TM system works well and the proposed algorithms are fine. The responses of slave manipulator are almost tracking with the reference input which is given from the motion of master manipulator.

The time delay is $100 \mathrm{~ms}$ with respected to sampling time to control via LAN and the error 
is acceptable which is approximation about $2 \%$ of amplitude of inputs.

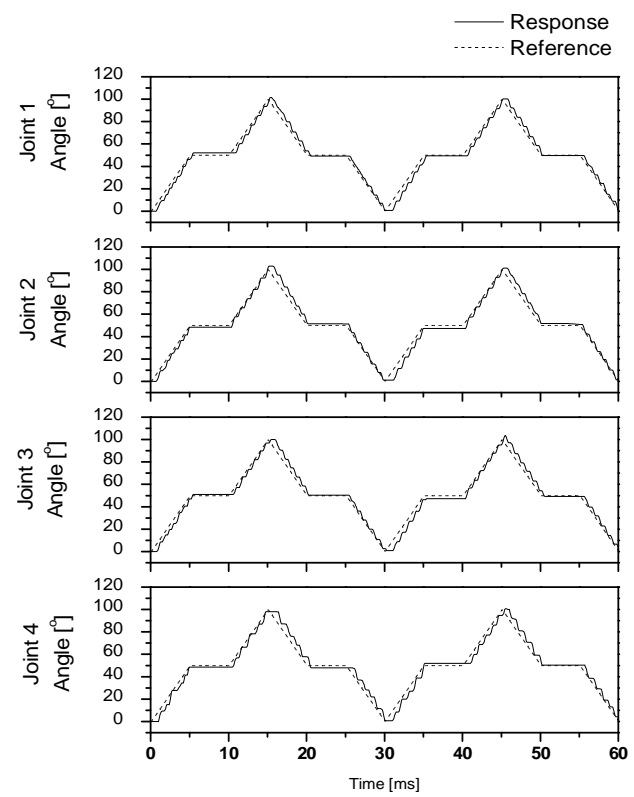

Fig 13. Triangle response of PID Controller

\section{CONCLUSIONS}

In this paper, a low cost TM system as well as network control algorithms are proposed. It is shown that the proposed control methods had a good performance for tele-operation manipulator. It can be seen from experimental results that the controller had stable and strong robustness.

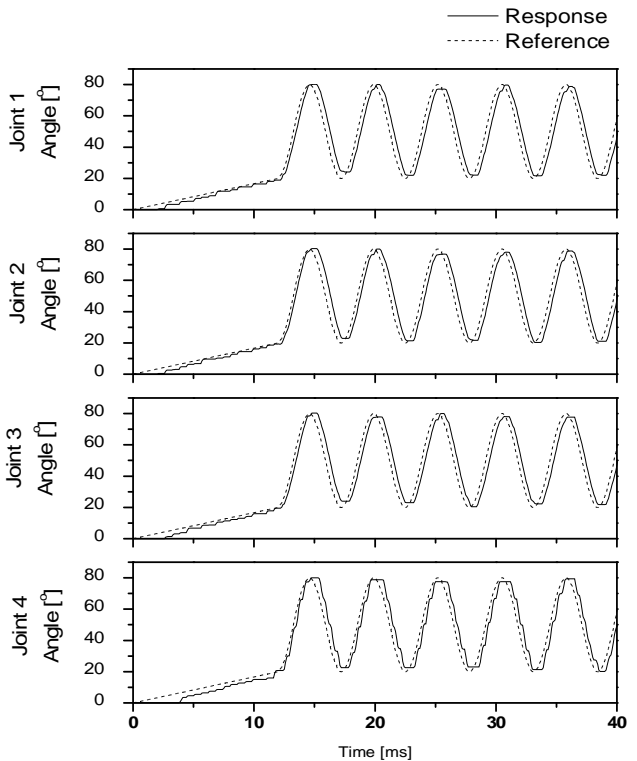

Fig 14. Sine response of PID Controller

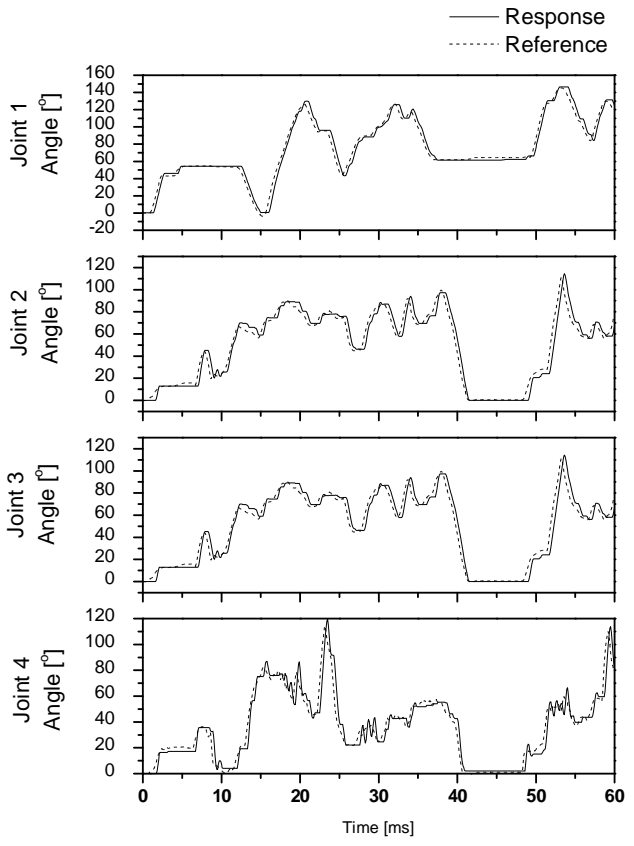

Fig 15. Real response of TM system

\section{Trang 32}


This study also show out the flowchart for PC server, PC Client as well as flowchart of low cost circuit using microcontroller PIC 18 F4450 and PIC 18F443.
From the experimental results, it shows that delay of response is given, and improvement control performance of system using intelligent control such as neural network or fuzzy logic will be applied in next study.

\section{ĐIỀU KHIỂN HOẠT ĐộNG TAY MÁY 4 BậC TÙ XA}

Từ Diệp Công Thành

Trường Đại học Bách Khoa, ĐHQG-HCM

TÓM TắT: Tay máy hoạt động tù xa được biết đến nhu là giải pháp tốt nhất cho các tương tác giũua con người với các môi trương không an toàn nhu nguy hiểm, độc hại, cách ly và vô trùng. Trong nghiên cứu này, một hệ thống tay máy điều khiển tù xa giá thành thấp được trình bày. Thêm nũa, giải thuật điều khiển qua mạng được đề xuất để điều khiển tù̀ xa.

Tù khóa: Hoạt động tù̀ xa, điều khiển, LAN.

\section{REFERENCES}

[1]. N. Tesla., Method of and Apparatus for Controlling Mechanism of Moving Vessels or Vehicles

http://www.pbs.org/tesla/res/613809.html (1898).

[2]. Raymond Goertz, R. Thompson, Electronically Controlled Manipulator, Nucleonics (1954).

[3]. A. K. Bejczy., Sensors, Controls, ManMachine Interface for Advanced Teleoperation, Science (1980).

[4]. R. D. Ballard., A last long look at Titanic, National Geographic, 170, 6 (1986).

[5]. A. Bejczy, G. Bekey, R. Taylor, S. Rovetta, A Research Methodology for
Tele- Surgery with Time Delays, First Int. Sym. on Medical Robotics and Computer Assisted Surgery (1994).

[6]. Dong-Soo Kwon, Ki Young Woo, Se Kyong Song, Wan Soo Kim, Hyung Suck Cho, Microsugical Telerobot system, Intelligent Robots and Systems, Proceedings., 1998 IEEE/RSJ International Conference, (1998).

[7]. Blake Hannaford, Diana Friedman, Hawkeye King,Mitch Lum, Jacob Rosen, Ganesh Sankaranarayanan, Evaluation of RAVEN Surgical Telerobot during the NASA Extreme Environment Mission Operations 12 Mission, Report of Dept of EE, University of Washington, (2009). 
[8]. Platon A. Prokopiou, Spyros G. Tzafestas, William S. Harwin, A Novel Scheme for Human-Friendly and Time-Delays Robust Neuropredictive Teleoperation, Journal of Intelligent and Robotic Systems, 25, 4, 311-340 (1999).

[9]. Lee, S., Lee, H. S., Modeling, design and evaluation of advanced teleoperator control systems with short time delay, IEEE Trans. Robotics Automat, 9, 607-623 (1993).

[10]. Sano, A., Fujimoto, H., Tanaka, M., Gainscheduled compensation for time delay of bilateral teleoperation, Proc. of IEEE
Internat. Conf. on Robot. Automat., Leuven, Belgium, 1916-1923 (1998).

[11]. Towhidkhah, F., Gander, R. E., Wood, H. C., Model predictive control: A model for joint movement, J. Motor Behavior, 29, 3, 209-222 (1997).

[12]. Prokopiou, P. A., Harwin, W. S., Tzafestas, S. G., Variable-time-delaysrobust telemanipulation through master state prediction, AIM '99: 1999 IEEE/ASME Internat, Conf. on Advan. Intel. Mechatronics, Atlanta, USA, 19-22 (1999). 